\title{
Effects of probiotics and Bidens pilosa on the performance and gut health of chicken during induced $\mathrm{E}$. tenella infection
}

Fareed Qamar Memon

Guangxi University https://orcid.org/0000-0002-3054-0687

\section{Yunqio Yang}

Guangxi University

Feifei Lv

Guangxi University

\section{A.M. Soliman}

Guangxi University

Yunru Chen

Guangxi University

Junying Sun

Guangxi University

Yuhan Wang

Guangxi University

Geyin Zhang

Guangxi University

Zheng Li

Guangxi University

Baichang Xu

Guangxi University

Javaid Ali Gadahi ( $\nabla$ drgadahi@yahoo.com )

Sindh Agriculture University

Hongbin Si ( $\nabla$ shb2009@gxu.edu.cn )

College of Animal Science and Technology, Guangxi University

Methodology article

Keywords: Probiotics, Bidens pilosa, Chickens, E.tenella, Performance, Gut health

Posted Date: March 23rd, 2020

DOl: https://doi.org/10.21203/rs.3.rs-18318/v1 
License: (c) (i) This work is licensed under a Creative Commons Attribution 4.0 International License. Read Full License 


\section{Abstract}

Background Probiotics and Medicinal plants are widely used as an alternative to treat different kinds of the acute and chronic diseases in all over the world. Bidens pilosa is commonly used as foods and therapeutics against various pathogens including protozoan. In the present study probiotics and Bidens pilosa were used to explore the anticoccidial activity during experimental infection of Eimeria tenella ( $E$. tenella ) in chicken Methods One hundred and fifty one-day-old Chinese yellow breed chickens were divided into five equal groups. Group 1 was kept as control group (CG; un-treated, unchallenged). All other groups were inoculated with E. tenella sporulated oocysts on day 21 of age. Group 2 was kept as positive control (CPG; un-treated, challenged). Group 3 was treated with probiotics (PG) at the rate of $1 \mathrm{~g} / \mathrm{kg}$ of feed. Group 4 was treated with Bidens pilosa (BPG) at the dose of $0.5 \% / \mathrm{kg}$ of feed. Group 5 was kept as probiotics + Bidens pilosa group (PG + BPG). All birds were weighed initially, day of infection and the final day of experiment. On day 5, 6, 7 and 8 post-infection (PI), bloody diarrhea was scored as normal (0) to sever (1, 2, 3 and 4), at the same time oocysts shedding was quantified by McMaster method. Gross caecal lesion scoring was checked at the final day of experiment. The apoptosis related gene expressions (Bcl-2, Bax, Caspase-3), anti-oxidant enzymatic expressions (CAT, SOD 1), Peptide transporter 1 (PepT 1), pro-inflammatory cytokines (IL-6, IL-8) and tight junction proteins expressions (CLDN 1, ZO 1) were checked by real time PCR. All related gene expressions average relative to $\beta$-actin was calculated by 2- $\Delta \Delta \mathrm{Ct}$ method. Results Birds treated with probiotics, Bidens pilosa and probiotics + Bidens pilosa slightly increased the body weight gain, significantly reduced oocysts shedding, destructive ratio of ceaca and mortality \% than control positive group. CPG birds up-regulated the expressions of Bcl-2 while downregulated the expressions of Bax and caspase-3 as compared to PG, BPG and PG + BPG groups. Moreover, Eimeria challenged chickens supplemented with probiotics, Bidens pilosa alone and combined showed higher anti-oxidant enzymatic activity than those of challenged un-treated chickens. Additionally, the expressions of pro-inflammatory cytokines and tight junction related proteins were also up-regulated by the treated challenged than un-treated challenged chickens. Conclusion Present results revealed that, feed supplementation of probiotics and Bides pilosa induced apoptosis, enhanced anti-oxidant enzymatic activity and pro-inflammatory cytokines as well as tight junction proteins and reduce mortality during E.tenella infection in chickens.

\section{Background}

Globally, intestinal parasitic infection is one of the major problem for domestic animal's health [1-3]. The apicomplexan phylum encompasses well known human and livestock pathogenic obligatory intracellular parasites, in which Eimeria is one of the most known genera, responsible for coccidiosis disease in both mammals and birds. Avian coccidiosis is an intestinal protozoan parasitic disease, causes bloody diarrhea, malabsorption, inefficient feed utilization, impaired growth rate, mortality and enhances susceptibility to other diseases such as necrotic enteritis. It causes a huge economic losses to the poultry industry ensuing more than 6 billion US dollars annually due to morbidity and mortality [4-6]. Chicken is susceptible for nine species of Eimeria including, E.tenell, E.nectrix, E.maxima, E.acervullina, E,mitis, 
E.praecox, E.brunetti, E. hagani and E. mivati. E.tenella is considered one of the most important pathogenic specie which destroys the epithelium of the caeca and causes serious gut homeostasis [7].

Currently, in the poultry industry, coccidiosis is commonly controlled by prophylaxis or anticoccidial agents and live vaccine $[6,8,9]$. However, due to increasing drug resistance and their residue in animal's food and food products, alternative strategies are needed to combat the coccidiosis $[10,11]$. In this regard, probiotics are being considered as excellent alternatives to control the disease and avoid the problems associated with the use of anticoccidial drugs and vaccines.

Probiotics are considered as live non-pathogenic microorganisms that are capable to maintain normal gastrointestinal microbiota $[12,13]$. Mode of action of probiotics is to increase the capability of GIT beneficial bacteria, immunity stimulation, increasing the activity of digestive enzymes, decreasing enzymatic activity and ammonia production and neutralization of enterotoxins [12,14-16]. Microflora in gastrointestinal tract play a vital role to local immunity stimulation, utilization of nutrients and inhibition of pathogenic bacterial colonization by competitive exclusion process and also have capability to release short-chain fatty acids and lactic acid by non-digestible fibers utilization to provide extra energy sources to host [17]. Studies reported that, gut microbiota can cause the alteration in pathophysiology of parasite infection to resist from enteric protozoan and its infection [18].

Medicinal plants and their products are deliberated as the backbone of traditional medicine and they are widely used as an alternative to treat different kinds of the acute and chronic diseases in all over the world [19]. Studies stated that about 1200 plants have anti-protozoal efficacy. To date, only 20 medicinal plants are used to treat coccidiosis [20-22]. Among them, species of the Bidens pilosa are commonly used as foods and therapeutics against almost 40 different diseases such as protozoan diseases, gastrointestinal diseases. Bidens pilosa is a flowering plant belonging from the Asteraceae family. About 200 different compounds are recognized from this plant, comprising terpenoids, flavonoids, porphyrin e.t.c. [23].

In the present study, effects of probiotics and Bidens pilosa on the performance and gut health of chicken during induced coccidial infection were evaluated.

\section{Methods}

\section{Collection and preservation of E.tenella}

Chicken coccidial infected caeca were collected from Gunagxi, China and crushed (whole caeca with feces) into water. After confirmation of E.tenella oocysts were isolated and washed with water by centrifugation at $3000 \mathrm{rpm}$ for 5 minutes. Isolated oocysts were preserved in $2.5 \%$ potassium dichromate and stored at room temperature for sporulation. After completing the sporulation process, the oocysts were stored at $4^{\circ} \mathrm{C}$ until inoculation.

Probiotics and Bidens pilosa 
Multi-strain probiotics was purchased from Kangjialong Feed co., LTD China (201906157), contained Bacillus subtilis, Clostridium butyricum and lactobacillus at $10 \times 10^{9} \mathrm{CFU} / \mathrm{g}$. It was supplemented from day one to end of the experiment at the rate of $1 \mathrm{~g} / \mathrm{kg}$ of feed.

Bidens pilosa was harvested from Nanning, China, and dried under drier, after drying the plant was mashed in powder form and given at the dose of $0.5 \mathrm{~g} / \mathrm{kg}$ of feed.

\section{Treatment plan}

One hundred and fifty one-day-old Chinese yellow breed chickens were purchased from hatchery and reared under battery cage system with ad-libitum admittance feed and water. They were divided into five equal groups, thirty birds/group each with three biological replicates (ten birds in each cage considered as one replicate). Group one was kept as control group (CG), un-treated, unchallenged. All other groups were inoculated with E.tenella sporulated oocysts orally at the dose of $1 \times 10^{6}$ on $21^{\text {st }}$ day of age. Group two was kept as control positive, un-treated group (CPG). Group three was supplemented continuously with probiotics (PG) at the rate of $1 \mathrm{~g} / \mathrm{kg}$ of feed. Group four was treated continuously with Bidens pilosa (BPG) at the dose of $0.5 \% / \mathrm{kg}$ of feed. Group five was kept as probiotics + Bidens pilosa group (PG + BPG), where, probiotics + Bidens pilosa were given continuously in feed the rate of $1 \mathrm{~g} / \mathrm{kg}+0.5 \% / \mathrm{kg}$ of feed.

\section{Body weight, bloody diarrhea and oocysts per gram of feces (OPG)}

All birds were weighed initially, day of infection (day 21 of age) and the final day of experiment (day 29 of age).

On day 5, 6, 7 and 8 post-infection (PI), bloody diarrhea was scored as normal (0) to sever (1, 2, 3 and 4), at the same time fresh fecal samples were collected from each cage in air tight plastic bag for oocysts counting and kept at $4{ }^{0} \mathrm{C}$ until oocysts counting. Oocysts were counted by McMaster Chamber slide as described by Hodgson [24].

\section{Mortality}

Dead birds were collected when observed, mortality was recorded and mortality \% was calculated.

\section{Caecal lesion scoring and sampling for gene mRNA expressions}

At the final day of experiment, 6 average birds/group ( 2 birds/replicate) were selected and euthanized by direct heart puncture. The caeca were collected for gross caecal lesion scoring according to the Johnson and Reid [25], where 0 is normal and 1, 2, 3 and 4 indicate severity of infection, also $2 \mathrm{~cm}$ caecal samples were collected for mRNA expressions and stored at $-80^{\circ} \mathrm{C}$ until further processing.

\section{Analysis of gene mRNA expressions}


TRIzol method was used to extract the total RNA according to the manufacturers recommendations. Quantification of the RNA was done by spectrophotometer (NanoDrop ND-1000) and then the RNA was transcribed to cDNA by using the reverse Transcription Kit (B639252-0100, Sangon Biotech co, Ltd, Shanghai, China). A total of 2 microgram of RNA was used to reverse into cDNA at 20 microgram of total amount (manufacturer's instructions). Reverse transcription reaction was performed by placing the samples under the PCR machine at $25^{\circ} \mathrm{C}$ for 5 minutes, $55^{\circ} \mathrm{C}$ for 15 minutes, followed by inactivation of enzyme at $85^{\circ} \mathrm{C}$ for 5 minutes and then all CDNA samples were kept at $-80^{\circ} \mathrm{C}$ to process it further. The mRNA expressions of the genes of interest were measured with quantitative real time PCR (7500 fluorescence qRT-PCR analysis, Applied Biosystem) by using 2xSG fast qPCR Master mix SYBR-green (B639271-0005, Sangon Biotech co, Ltd, Shanghai, China) to quantify the apoptosis related proteins expressions (Bcl-2, Bax, Caspase-3), anti-oxidant enzymatic expressions (CAT, SOD 1), Peptide transporter 1 (PepT 1), pro-inflammatory cytokines (IL-6, IL-8), ) and tight junction proteins expressions (CLDN 1, ZO 1). Genes and there specific primers are shown in table 1 . $\beta$-actin was used as control gene and all samples gene expressions average relative to $\beta$-actin was calculated by $2-\Delta \Delta C t$ method [26].

Table 1 Primer Sequences used for Quantitative Real Time PCR

\begin{tabular}{|c|c|c|c|}
\hline Genes & & Primer Sequence (5_3」) & Gene Bank ID \\
\hline \multirow[t]{2}{*}{$\beta$-actin } & F: & GAGAAATTGTGCGTGACATCA & \\
\hline & R: & ССТGAАССТСТСАТTGCСА & L08165 \\
\hline \multirow[t]{2}{*}{ Bcl-2 } & F: & GATGACCGAGTACCTGAACC & \\
\hline & $\mathrm{R}:$ & CAGGAGAAATCGAACAAAGGC & NM205339 \\
\hline \multirow[t]{2}{*}{ BAX } & F: & TCCTCATCGCCATGCTCAT & \\
\hline & R: & CCTTGGTCTGGAAGCAGAAGA & XM422067 \\
\hline \multirow[t]{2}{*}{ Caspase-3 } & F: & TGGCCCTCTTGAACTGAAAG & \\
\hline & R: & TCCACTGTCTGCTTCAATACC & NM204725 \\
\hline \multirow[t]{2}{*}{ CAT } & F: & GAGGAACCCTCAGACTCATTTG & \\
\hline & R: & CCATCAGGAATACCACGATCAC & NM_001031215.2 \\
\hline \multirow[t]{2}{*}{ SOD 1} & F: & AGATGGCAGTGGGAAATGAG & \\
\hline & R: & ACTCAAGACAGCAGAGTAGTAATG & NM 205064.1 \\
\hline \multirow[t]{2}{*}{ PepT 1} & $\mathrm{~F}:$ & СCCCTGAGGAGGATCACTGTT & \\
\hline & $\mathrm{R}:$ & CAAAAGAGCAGCAGCAACGA & \\
\hline \multirow[t]{2}{*}{ CLDN 1} & F: & ACTCCTGGGTCTGGTTGGT & KF366603.1 \\
\hline & R: & CAGGTCAAACAGAGGTACAGG & \\
\hline \multirow[t]{2}{*}{ ZO 1} & F: & CTTCAGGTGTTTCTCTTCCTCCTC & AY750897.1 \\
\hline & R: & CTGTGGTTTCATGGCTGGATC & \\
\hline \multirow[t]{2}{*}{ IL-6 } & F: & GCTCGCCGGCTTCGA & \\
\hline & R: & GGTAGGTCTGAAAGGCGAACAG & XM_413773 \\
\hline \multirow[t]{3}{*}{ IL-8 } & F: & CACGTTCAGCGATTGAACTC & \\
\hline & R: & GACTTCCACATTCTTGCAGTG & HM1 79640.1 \\
\hline & & & AJ009800 \\
\hline
\end{tabular}




\section{Statistical analysis}

Collected data was analyzed on JMP 8.1 and prism software for one way ANOVA test and was subjected to Tukey test to compare the means for significant differences observation.

\section{Results}

\section{Body weight gain}

The results of body weight gain are shown in Figure 1. The body weight of the birds supplemented with probiotics, Bidens pilosa and probiotics + Bidens pilosa was increased slightly but not affected significantly during 0-21 day and 21-29 of age. Untreated and challenged birds (CP) significantly decreased $(P<0.005)$ the body weight during day 21-29 of age when compared control negative group (Figure 1)

\section{Oocysts Shedding}

The effect of probiotics, Bidens pilosa and probiotics + Bidens pilosa on oocysts shedding is shown in Figure 2. All treated groups significantly $(P<0.005)$ decreased oocysts counting/gram of feces during the day 4-8 post-infection relative to un-treated challenged control positive group. However, no oocysts were counted in group control negative untreated un-challenged birds feces. The highest OPG values were observed on day 8 post-infection.

\section{Lesion Score}

Dramatic collaboration effect on caecal lesion score between treated infected and un-treated infected is shown in Figure 3. Where probiotics, Bidens pilosa and probiotics + Bidens pilosa revealed significant $(\mathrm{P}<$ 0.005) reduction in the caecal lesions with the comparison of control positive birds, whereas, no significant difference was observed among treated groups. No lesions were seen in the caeca of control negative untreated unchallenged birds (Figure 3).

\section{Apoptosis Related Proteins Expressions}

Figure 4 shows the results of Bcl-2, Bax and Caspase-3 (apoptosis related proteins). Eimeria challenged un-treated significantly $(\mathrm{P}<0.005)$ up-regulated mRNA expressions of $\mathrm{Bcl}-2$ and down-regulated Bax proteins expressions birds than those of birds treated with probiotics, Bidens pilosa and Probiotics + Bidens pilosa and as shown in Figure 4-A and 4-B. On the other hand, the expressions of Caspase-3 were slightly up-regulated in treated groups but not significantly affected among all groups (Figure 4-C).

\section{Anti-oxidant Enzymatic and Peptide Transporter 1 (PepT 1) Expressions}


Changes in CAT, SOD 1, PepT 1 expressions are shown in Figure 5. Significant $(P<0.005)$ interaction influence on anti-oxidative enzymatic and Peptide Transporter $1 \mathrm{mRNA}$ expressions were perceived between treated positive and un-treated positive groups, where group CG showed higher anti-oxidant enzymatic and PepT 1 activity relative to all other groups. Compared to infected un-treated birds, group PG, BPG and PG + BPG significantly increased the CAT and PepT 1 activity, while SOD 1 activity in BPG group alone (Figure 5-A, 5-B and 5-C). However, PG and PG + BPG groups were slightly increased SOD 1 activity with the comparison of CPG group but no significant interaction effect was observed among them (Figure 5-B).

\section{Tight Junction Proteins and Pro-inflammatory Cytokines Expressions}

mRNA expressions of tight junction proteins (CLDN 1, ZO 1) and Pro-inflammatory Cytokines (IL-6, IL-8) are shown in Figure 6. Groups treated with probiotics and probiotics + Bidens pilosa significantly $(P<$ 0.005) up-regulated ZO 1, IL-6 and IL-8 expressions, while treatment of Bidens pilosa alone increased ZO1 and IL-6 expressions significantly $(P<0.005)$ relative to un-treated un-challenged and un-treated challenged groups (Figure 6-B, 6-C and 6-D). However, no significant interface of CLDN 1 expressions was observed between all groups (Figure 6-A).

\section{Mortality}

No mortality was found in CG group. Maximum mortality \% was recorded in group CPG in the comparison of all other groups, however, no significant interaction was observed between treated challenged and control group (Figure 7).

\section{Discussion}

Under the natural conditions, coccidiosis in avian is caused by several eimerian species and is one of the most potential disparaging disease in birds [27], causing substantial economic losses to poultry industry. Misuse of anti-coccidial drugs has elevated public apprehensions about food safety. Probiotics and herbs are evolving as alternative strategies to control the Eimeria infection in chickens $[20,28]$. In current experiment we had investigated the combined and individual efficacy of probiotics and Bidens pilosa on induced E.tenella infection in Chinese yellow breed chickens. Our results demonstrated that birds received probiotics, Bidens pilosa and probiotics + Bidens pilosa were increased the body weight gain, reduced the fecal oocysts shedding and destructive ratio of ceaca than control positive un-treated challenged birds. Currently in animal industry, Probiotics and herbs have been supplemented to treat numerous gut diseases and exert constructive effects on animal's health. Ritzi et al [29] stated that, multi-strain probiotics treatment improves body weight gain, decreases the oocysts excretion and the intestinal lesions during Eimeria species infection. Probiotics feeding has been proven to be effective similarly as an anti-coccidial drug in the aspect of oocysts shedding and lesion scoring, which indicates of healthier intestine. Probiotics bacteria may inhabit common receptors on the intestinal epithelium by opposing for attachment sites, which causes inhibition of Eimeria replication and consequently shedding [30]. Probiotics treatment enhanced protective immunity against coccidiosis which resulting protection 
against pathological effects of Eimeria [31, 32]. Yang et al [33] reported that, treatment of Bidens pilosa improved the condensed growth rate of Eimeria, reduced the oocysts shedding and simultaneously intestinal lesions in challenged chickens. This efficacy of Bidens pilosa can be ascribed to control coccidiosis and it's negative impacts. Bidens pilosa supplementation effect on chicken weight gaining reflects its usability as food and nutritional importance [23].

Nature of the Apicomplexan parasites is to inhibit the apoptosis related mechanism via regulating antiapoptosis factors to survive and grow inside the host cell [34]. E.tenella has capability to prompt antiapoptosis factor $\mathrm{Bcl}-\mathrm{xL}$ and nuclear transcriptional factor NF-KB to protect their cells and growing in its second generation schizonts and can be act as antagonists by enhancing the activity of NF-KB which is responsible for regulating numerous anti-apoptosis proteins such as $\mathrm{Bcl}-\mathrm{xL}, \mathrm{Bcl}-2$ and $\mathrm{Mcl}-1$ [35]. Previous studies reported that Probiotics and herbs revealed ameliorative effects on apoptosis by prompting proapoptosis proteins conversely inhibiting anti-apoptosis elements [36, 37]. In order to search the apoptotic mechanism between treated and un-treated chickens, we have explored the expressions of Bcl-2, Bax and Caspase-3. Our study demonstrated that birds received probiotics and Bidens pilosa individual and combined up-regulated the expressions of Bax and caspase- 3 and down-regulated Bcl-2 with the comparison of challenged un-treated birds (Fig. 4). Yaser et al [38] investigated the probiotics supplementation efficacy on pro-apoptosis and anti-apoptosis proteins gene expressions to treat colon cancer in animal model. They reported that, infected animals treated with probiotics enhanced the expressions of Bax and caspase- 3 besides decreased the anti-apoptosis Bcl-2 protein expressions. Shen et al [39] examined the anti-cancer mechanism of ether extract from Bidens pilosa to induce apoptosis and detected down-regulated expressions of $\mathrm{Bcl}-2$ and up-regulated expressions of Bax and caspase-3. Apoptosis induction is a new therapeutic treatment direction against many disorders $[40,41]$. Active apoptotic proteins lead to spike numerous target proteins of cells and interruption cellular components [42].

In the present study we also examined the anti-oxidant enzymatic activity among treated and untreatment challenged conditions. Our results showed higher mRNA expressions of CAT and SOD 1 in groups treated with probiotics and Bidens pilosa separately and combined as is shown in Fig. 5. Previous researches have stated that, Bidens pilosa and probiotics increase the down-regulated anti-oxidant enzymatic activity during infection $[43,44]$. Anti-oxidant enzymes such as CAT and SOD are the most important enzymes of the body, which protect against oxidative stress by the degradation of hydrogen peroxide and superoxide anions [45]. In addition, intestinal mucosal anti-oxidative proficiency is also critical for healthier intestine [46]. Lower expressions of ant-oxidant enzymes can be caused by the production of nitric oxide (NO) resulting of intestinal cellular destruction, which refers the anti-oxidant capacity of the defense system would be exceeded during Eimeria infection[47]. Maximum anti-oxidant activity leads to conflict the free radicals during infection [48].

Cytokines are prevailing in the gastro intestinal tract (GIT) normally as elements and modulators of immune pathology. The GIT is proposed a promising source of pro-inflammatory cytokines under several pathological conditions [49]. In the present work, mRNA expressions of pro-inflammatory cytokines IL-6 
and IL-8 were influenced by treatment and without treatment challenged, where treated groups upregulated the expressions of IL-6 and IL-8 relative to un-treated chickens (Fig. 6-A, 6-B). Probiotics have been shown to normalize the down-regulated levels of cytokines. Wnag et al [36] stated that, probiotics enhanced the expressions of pro-inflammatory interleukins during infection. Zhang et al [50] reported that, Bidens pilosa aqueous extract up-regulated the inflammatory cytokines during traetmental trail. Cytokines have been associated with the modulation of enteritis and the permeability of intestine. Several studies suggested that cytokines increase the functional activity of intestinal barrier and regulate tight junction proteins [51]. Tight junction proteins including occludin (OCLN), zonula occludins (ZO), claudins (CLDN) junctinal adhesion molecules proteins play a vital role in the intestinal epithelial cell barrier, which defend host's intestine from pathogens and avoids the transmission of macromolecules [52]. In the present study, E.tenella chellanged un-treated group (CPG) decreased the expressions of CLDN 1 and ZO 1 as compared to PG, BPG and PG + BPG groups (Fig. 6-C, 6-D). These findings are consistent with previous reports, which revealed that tight junction proteins were increased by probiotics and herbal supplementation [28, 53].

\section{Conclusion}

Feed supplementation of probiotics and Bidens pilosa alone and combined prevent the negative impacts of Eimeria on the performance and intestinal functions. Our results showed for the $1 \mathrm{st}$ time that probiotics and herbs combined and individual are able to protect the caeca under E.tenella challenge in order to induce apoptosis, enhance anti-oxidant enzymatic activity, up-regulation level of tight junction proteins and interleukins. Better efficacy was achieved in group Probiotics challenged and Probiotics + Bidens pilosa challenged. No synergistic and nor antagonists effect was found when probiotics and Bidens pilosa supplemented together.

\section{Abbreviations}

E.tenella: Eimeria tenella; CG: Control group; CPG: Control positive group un-treated challenged; PG: Probitics group; BPG: Bidens pilosa group; PG + BPG: Probiotics + Bidens pilosa group; PI: Post-infection; Bcl-2: B-cell lymphoma; CAT: Catalase; SOD 1: Superoxide dismutase 1; PepT: Peptide transporter 1: IL-6: Interleukin 6; IL-8: Interleukin 8; CLDN 1: Claudin 1; ZO 1: Zonula occludens 1; $\beta$-actin: Beta actin; RNA: Ribonucleic acid; cDNA: Complementary Deoxyribonucleic Aciid; mRNA: Messenger Ribonucleic Acid; qRTPCR: quantitative real time polymerase chain reaction; qPCR: Quantitative polymerase chain reaction

\section{Declarations}

\section{Acknowledgement}

This work was supported by the Science and Technology Major Project of Guangxi, China (AA17204057) National Natural Science Foundation of China (31760746) and the Key Research and Development Plan of Guangxi, China (AB19245037) 


\section{Data Availability Statement}

The data supporting with the findings of this study is available from the corresponding authors on reasonable request

\section{Conflict of interest}

Fareed Qamar Memon, Yunqiao Yang, Feifei Lv, A.M. Soliman, Yunru Chen, Junying Sun, Yuhan Wang, Geyin Zhang, Zheng Li, Baichang Xu, Javaid Ali Gadahi and Hongbin Si declare that, they have no conflict of interest

\section{Authors' contributions}

Fareed Qamar Memon and Yunqiao Yang are equally contributed to this work and conducted all the experiments. Hongbin Si supervised all experimental conditions. Feifei Lv,Yuhan Wang, Geyin Zhang and Zheng $\mathrm{Li}$, helped to slaughter the birds and collect organs. Yunru Chen, Baichang Xu and Junying Sun helped to extract the RNA, find the gene sequencing and done qPCR. Javaid Ali Gadahi and A.M. Soliman reviewed and revised the manuscript.

\section{Authors Detail}

${ }^{1}$ Department of Clinical Veterinary Medicine, College of Animal Science and Technology, Guangxi University, Nanning, China

${ }^{2}$ Department of Veterinary Parasitology, Sindh Agriculture University Tando jam, Sindh, Pakistan

\section{Ethical Statement}

All experimental conditions for animals were performed according to the guidelines approved by the Animal Care and Use Committee of Guangxi University, Nanning, China

\section{References}

1. Di Bella JM, Bao Y, Gloor GB, Burton JP, Reid G. High throughput sequencing methods and analysis for microbiome research. J Microbiol Methods. 2013;

2. Macpherson AJ, Harris NL. Interactions between commensal intestinal bacteria and the immune system. Nat. Rev. Immunol. 2004.

3. van Dooren GG, Striepen B. The Algal Past and Parasite Present of the Apicoplast. Annu Rev Microbiol. 2013;

4. Lillehoj HS, Lillehoj EP. Avian Coccidiosis. A Review of Acquired Intestinal Immunity and Vaccination Strategies. Avian Dis. 2000; 
5. Dalloul RA, Lillehoj HS. Poultry coccidiosis: Recent advancements in control measures and vaccine development. Expert Rev. Vaccines. 2006.

6. Chapman HD. Milestones in avian coccidiosis research: A review. Poult. Sci. 2014.

7. Chapman HD, Cherry TE, Danforth HD, Richards G, Shirley MW, Williams RB. Sustainable coccidiosis control in poultry production: The role of live vaccines. Int J Parasitol. 2002.

8. Mcdougald LR. Intestinal Protozoa Important to Poultry. Poult Sci. 1998;

9. Chapman HD. Use of anticoccidial drugs in broiler chickens in the USA: Analysis for the years 1995 to 1999. Poult Sci. 2001;

10. Abbas RZ, Iqbal Z, Blake D, Khan MN, Saleemi MK. Anticoccidial drug resistance in fowl coccidia: The state of play revisited. Worlds. Poult. Sci. J. 2011.

11. Cosby DE, Cox NA, Harrison MA, Wilson JL, Jeff Buhr R, Fedorka-Cray PJ. Salmonella and antimicrobial resistance in broilers: A review. J. Appl. Poult. Res. 2015.

12. Patterson JA, Burkholder KM. Application of prebiotics and probiotics in poultry production. Poult Sci. 2003.

13. Ohimain El, Ofongo RTS. The Effect of Probiotic and Prebiotic Feed Supplementation on Chicken Health and Gut Microflora: A Review. Int J Anim Vet Adv. 2012;

14. Walker WA, Duffy LC. Diet and bacterial colonization: Role of probiotics and prebiotics.

15. Nutr. Biochem. 1998.

16. Collins MD, Gibson GR. Probiotics, prebiotics, and synbiotics: Approaches for modulating the microbial ecology of the gut. Am J Clin Nutr. 1999.

16. Simmering R, Blaut M. Pro- and prebiotics - The tasty guardian angels? Appl. Microbiol. Biotechnol. 2001.

17. Wang X, Farnell YZ, Kiess AS, Peebles ED, Wamsley KGS, Zhai W. Effects of Bacillus subtilis and coccidial vaccination on cecal microbial diversity and composition of Eimeria-challenged male broilers. Poult Sci. 2019;

18. Huang G, Zhang S, Zhou C, Tang X, Li C, Wang C, et al. Influence of Eimeria falciformis infection on gut microbiota and metabolic pathways in mice. Infect Immun. 2018;

19. Mazumder MEH, Rahman S. Pharmacological evaluation of Bangladeshi medicinal plants for antioxidant activity. Pharm Biol. 2008;

20. Muthamilselvan T, Kuo TF, Wu YC, Yang WC. Herbal remedies for coccidiosis control: A review of plants, compounds, and anticoccidial actions. Evidence-based Complement. Altern. Med. 2016. 
21. Willcox ML, Bodeker G. Traditional herbal medicines for malaria. Br. Med. J. 2004.

22. Orengo J, Buendía AJ, Ruiz-lbáñez MR, Madrid J, Del Río L, Catalá-Gregori P, et al. Evaluating the efficacy of cinnamaldehyde and Echinacea purpurea plant extract in broilers against Eimeria acervulina. Vet Parasitol. 2012;

23. Bartolome AP, Villaseñor IM, Yang WC. Bidens pilosa L. (Asteraceae): Botanical properties, traditional uses, phytochemistry, and pharmacology. Evidence-based Complement. Altern. Med. 2013.

24. Hodgson JN. Coccidiosis: Oocyst counting technique for coccidiostat evaluation. Exp Parasitol. 1970;

25. Johnson J, Reid WM. Anticoccidial drugs: Lesion scoring techniques in battery and floor-pen experiments with chickens. Exp Parasitol. 1970;

26. Livak KJ, Schmittgen TD. Analysis of relative gene expression data using real-time quantitative PCR and the 2- $\triangle \Delta C T$ method. Methods. 2001;

27. Morris GM, Gasser RB. Biotechnological advances in the diagnosis of avian coccidiosis and the analysis of genetic variation in Eimeria. Biotechnol. Adv. 2006.

28. Li Z, Wang W, Liu D, Guo Y. Effects of Lactobacillus acidophilus on the growth performance and intestinal health of broilers challenged with Clostridium perfringens. J Anim Sci Biotechnol. 2018;

29. Ritzi MM, Abdelrahman W, Mohnl M, Dalloul RA. Effects of probiotics and application methods on performance and response of broiler chickens to an Eimeria challenge. Poult Sci. 2014;

30. Abdelrahman W, Mohnl M, Teichmann K, Doupovec B, Schatzmayr G, Lumpkins B, et

31. Comparative evaluation of probiotic and salinomycin effects on performance and coccidiosis control in broiler chickens. Poult Sci. 2014;

31. Dalloul RA, Lillehoj HS, Shellem TA, Doerr JA. Intestinal Immunomodulation by Vitamin A Deficiency and Lactobacillus-Based Probiotic in Eimeria acervulina-Infected Broiler Chickens. Avian Dis. 2003;

32. Dalloul RA, Lillehoj HS, Tamim NM, Shellem TA, Doerr JA. Induction of local protective immunity to Eimeria acervulina by a Lactobacillus-based probiotic. Comp Immunol Microbiol Infect Dis. 2005;

33. Yang WC, Tien YJ, Chung CY, Chen YC, Chiou WH, Hsu SY, et al. Effect of Bidens pilosa on infection and drug resistance of Eimeria in chickens. Res Vet Sci. 2015;

34. Del Cacho E, Gallego M, López-Bernad F, Quílez J, Sánchez-Acedo C. Expression of anti-apoptotic factors in cells parasitized by second-generation schizonts of Eimeria tenella and Eimeria necatrix. Vet Parasitol. 2004; 
35. Yu S, Gong L sheng, Li N feng, Pan Y feng, Zhang L. Galangin (GG) combined with cisplatin (DDP) to suppress human lung cancer by inhibition of STAT3-regulated NF-KB and Bcl-2/Bax signaling pathways. Biomed Pharmacother. 2018;

36. Wang L, Liu C, Chen M, Ya T, Huang W, Gao P, et al. A novel Lactobacillus plantarum strain P-8 activates beneficial immune response of broiler chickens. Int Immunopharmacol. 2015;

37. Jiao JY, Yang YQ, Liu MJ, Li JG, Cui Y, Yin SJ, et al. Artemisinin and Artemisia annua leaves alleviate Eimeria tenella infection by facilitating apoptosis of host cells and suppressing inflammatory response. Vet Parasitol. 2018;

38. Gamallat Y, Meyiah A, Kuugbee ED, Hago AM, Chiwala G, Awadasseid A, et al. Lactobacillus rhamnosus induced epithelial cell apoptosis, ameliorates inflammation and prevents colon cancer development in an animal model. Biomed Pharmacother. 2016;

39. Shen Y, Sun Z, Shi P, Wang G, Wu Y, Li S, et al. Anticancer effect of petroleum ether extract from Bidens pilosa $L$ and its constituent's analysis by GC-MS. J Ethnopharmacol. 2018;

40. Elmore S. Apoptosis: A Review of Programmed Cell Death. Toxicol. Pathol. 2007.

41. Sakatani A, Fujiya M, Ueno N, Kashima S, Sasajima J, Moriichi K, et al. Polyphosphate derived from lactobacillus brevis inhibits colon cancer progression through induction of cell apoptosis. Anticancer Res. 2016;

42. Tong Y, You L, Liu H, Li L, Meng H, Qian Q, et al. Potent antitumor activity of oncolytic adenovirus expressing Beclin-1 via induction of autophagic cell death in leukemia. Oncotarget. 2013;

43. Yuan LP, Chen FH, Ling L, Dou PF, Bo H, Zhong MM, et al. Protective effects of total flavonoids of Bidens pilosa L. (TFB) on animal liver injury and liver fibrosis. J Ethnopharmacol. 2008;

44. Wang H, Ni X, Qing X, Liu L, Lai J, Khalique A, et al. Probiotic enhanced intestinal immunity in broilers against subclinical necrotic enteritis. Front Immunol. 2017;

45. Shen X, Yi D, Ni X, Zeng D, Jing B, Lei M, et al. Effects of lactobacillus plantarum on production performance, immune characteristics, antioxidant status, and intestinal microflora of bursinimmunized broilers. Can J Microbiol. 2014;

46. Marnett LJ. Lipid peroxidation - DNA damage by malondialdehyde. Mutat Res - Fundam Mol Mech Mutagen. 1999;

47. Çam Y, Atasever A, Eraslan G, Kibar M, Atalay Ö, Beyaz L, et al. Eimeria stiedae: Experimental infection in rabbits and the effect of treatment with toltrazuril and ivermectin. Exp Parasitol. 2008;

48. Allen PC, Fetterer RH. Interaction of dietary vitamin E with Eimeria maxima infections in chickens. Poult Sci. 2002; 
49. Navasa M, Follo A, Filella X, Jiménez W, Francitorra A, Planas R, et al. Tumor necrosis factor and interleukin-6 in spontaneous bacterial peritonitis in cirrhosis: Relationship with the development of renal impairment and mortality. Hepatology. 1998;

50. Zhang C, Li K, Yang Z, Wang Y, Si H. The Effect of the Aqueous Extract of Bidens Pilosa L. on Androgen Deficiency Dry Eye in Rats. Cell Physiol Biochem. 2016;

51. Al-Sadi R, Ye D, Dokladny K, Ma TY. Mechanism of IL-1 $\beta$-Induced Increase in Intestinal Epithelial Tight Junction Permeability. J Immunol. 2008;

52. Schneeberger EE, Lynch RD. The tight junction: A multifunctional complex. Am. J. Physiol. - Cell Physiol. 2004.

53. Park K II, Kim DG, Lee BH, Ma JY. Fermented Herbal Formulas KIOM-MA128 Ameliorate IL-6-Induced Intestinal Barrier Dysfunction in Colon Cancer Cell Line. Mediators Inflamm. 2016;

\section{Figures}




\section{Body Weight Gain}

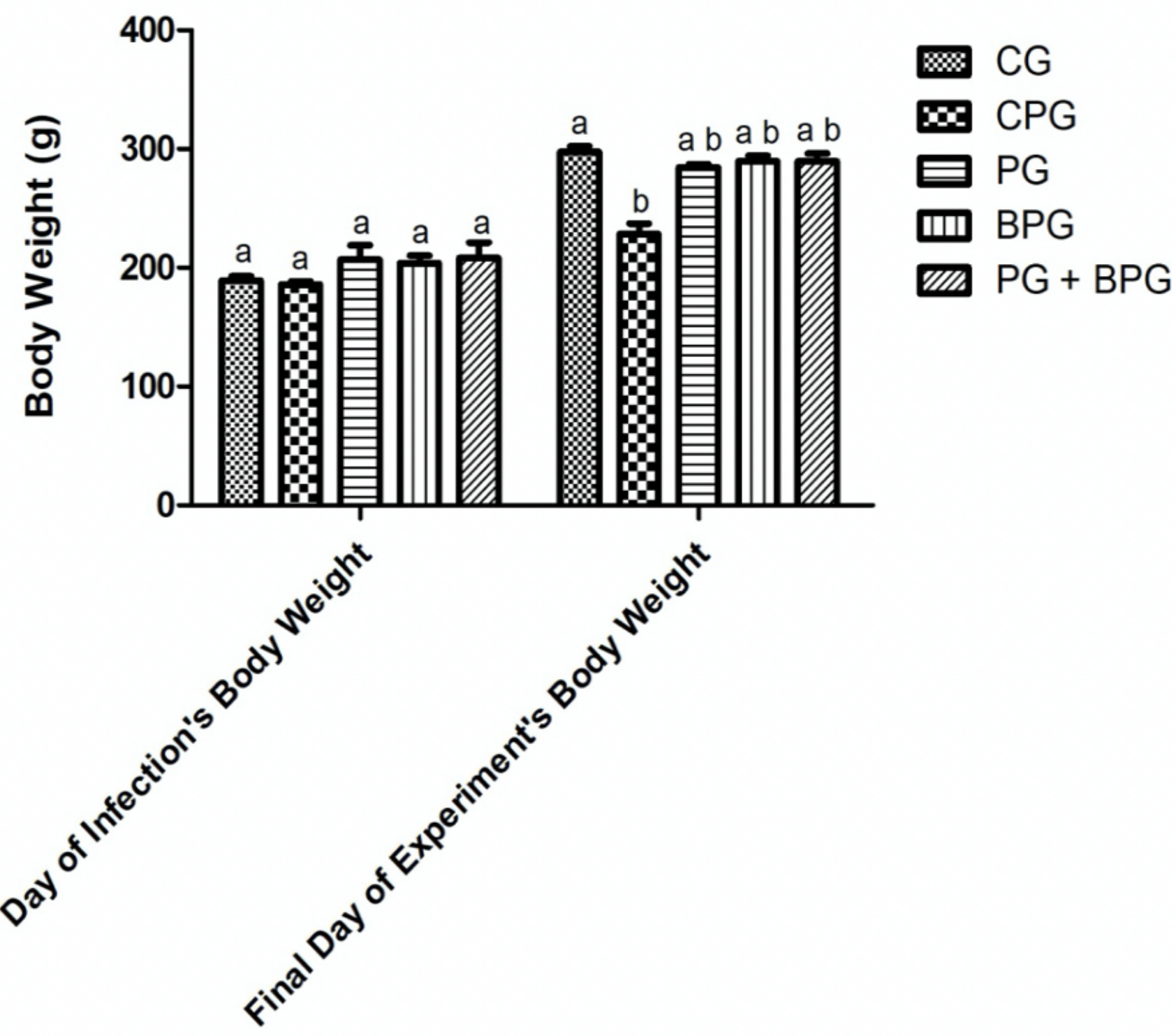

Figure 1

shows the average body weight gain of treated and un-treated groups. Results are presented as mean and standard error of mean. Present superscripts $(a, b)$ show significant difference $((P<0.005)$ among the groups. $\mathrm{CG}=$ Control group; $\mathrm{CPG}=$ Control positive group; $\mathrm{PG}=$ Probiotics group; $\mathrm{BPG}=$ Bidens pilosa group; $P G+B P G=$ Probiotics + Bidens pilosa group. 


\section{Oocysts Counting}

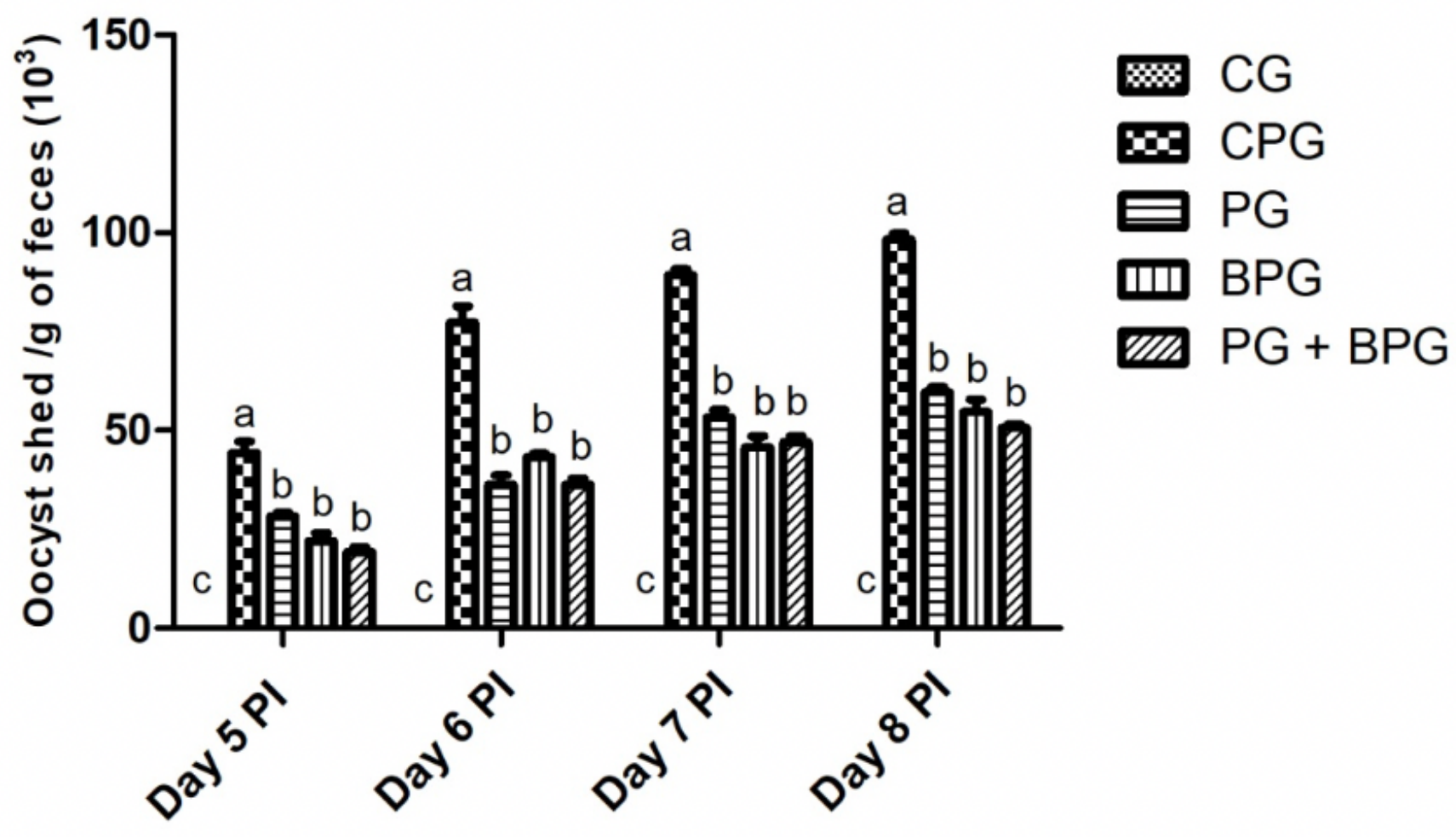

Figure 2

shows the oocysts counting/g feces of treated and un-treated groups between day 4-8 post-infection. Results are presented as mean and standard error of mean. Present superscripts (a-c) show significant difference $((P<0.005)$ among the groups. $C G=$ Control group; $C P G=$ Control positive group; $P G=$ Probiotics group; $B P G=$ Bidens pilosa group; $P G+B P G=$ Probiotics + Bidens pilosa group . 


\section{Caecal Lesion Score}

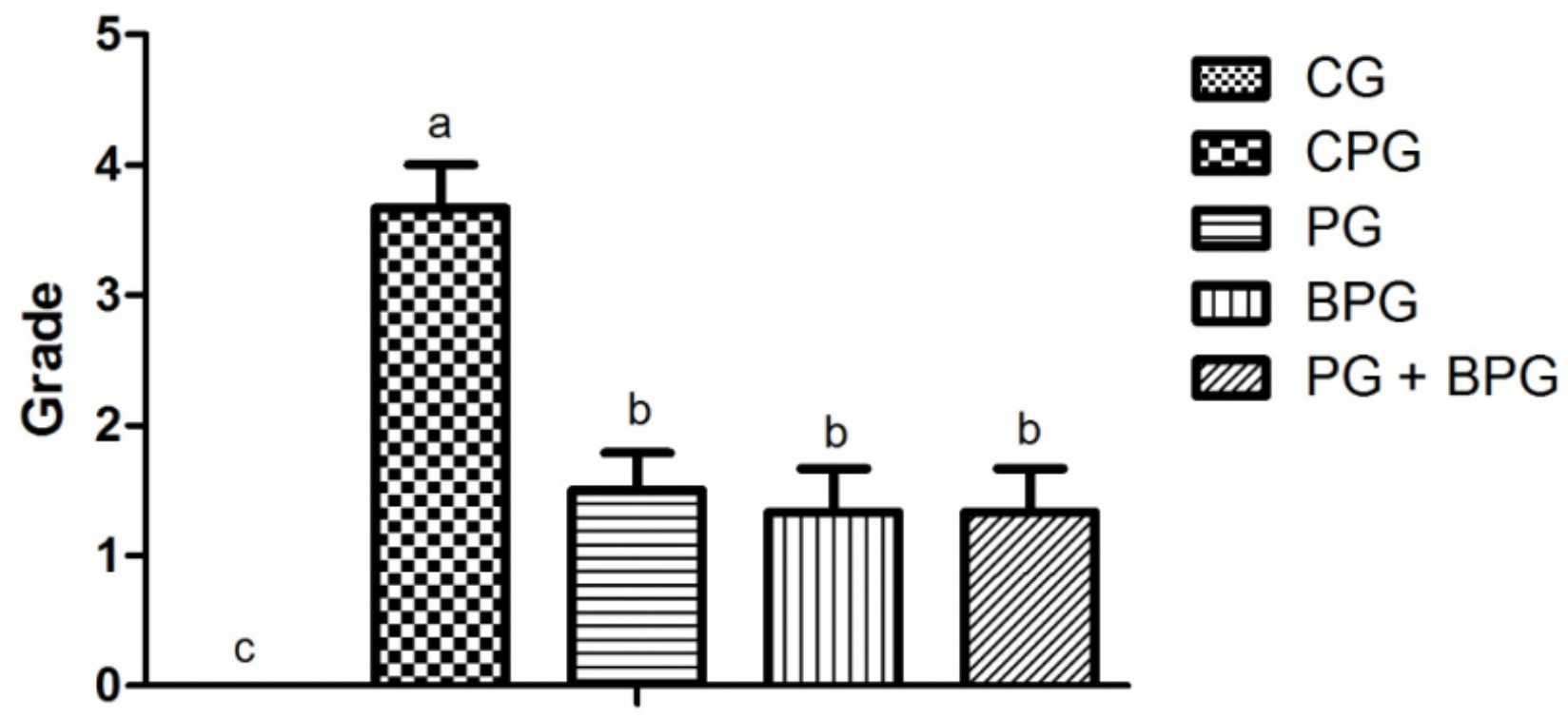

Figure 3

shows the severity of the ceacal lesions among treated and un-treated groups. Results are presented as mean and standard error of mean. Present superscripts $(a, b)$ show significant difference $((P<0.005)$ among the groups. $\mathrm{CG}=$ Control group; $\mathrm{CPG}=$ Control positive group; $\mathrm{PG}=$ Probiotics group; $\mathrm{BPG}=$ Bidens pilosa group; $P G+B P G=$ Probiotics + Bidens pilosa group . 


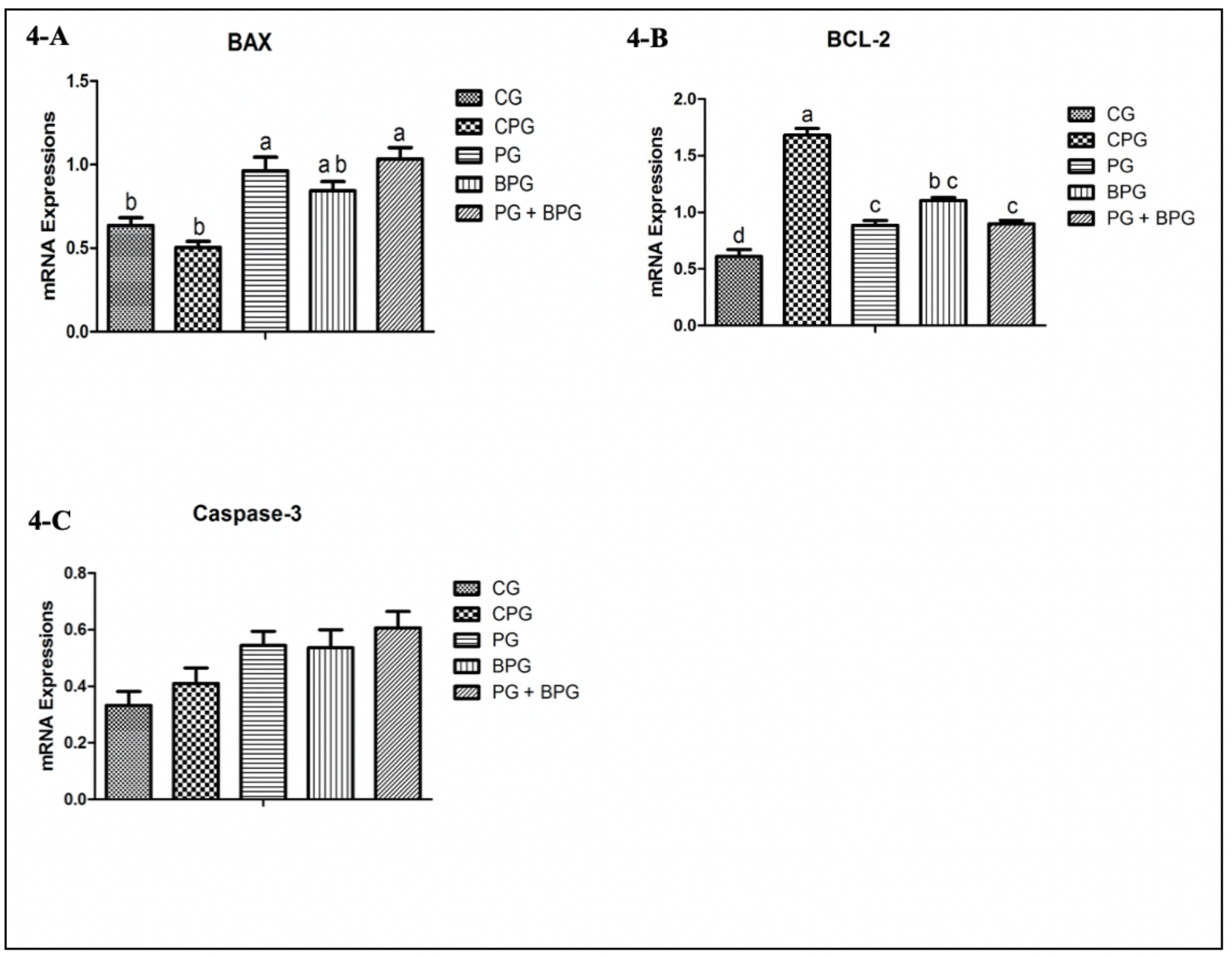

Figure 4

Apoptosis related proteins mRNA expressions in the caeca of un-treated and treated challenged are presented in Figure 4. Results are presented as mean and standard error of mean. Present superscripts (ac) show significant difference $((P<0.005)$ among the groups. $C G=$ Control group; $C P G=$ Control positive group; $P G=$ Probiotics group; $B P G=$ Bidens pilosa group; $P G+B P G=$ Probiotics + Bidens pilosa group . 


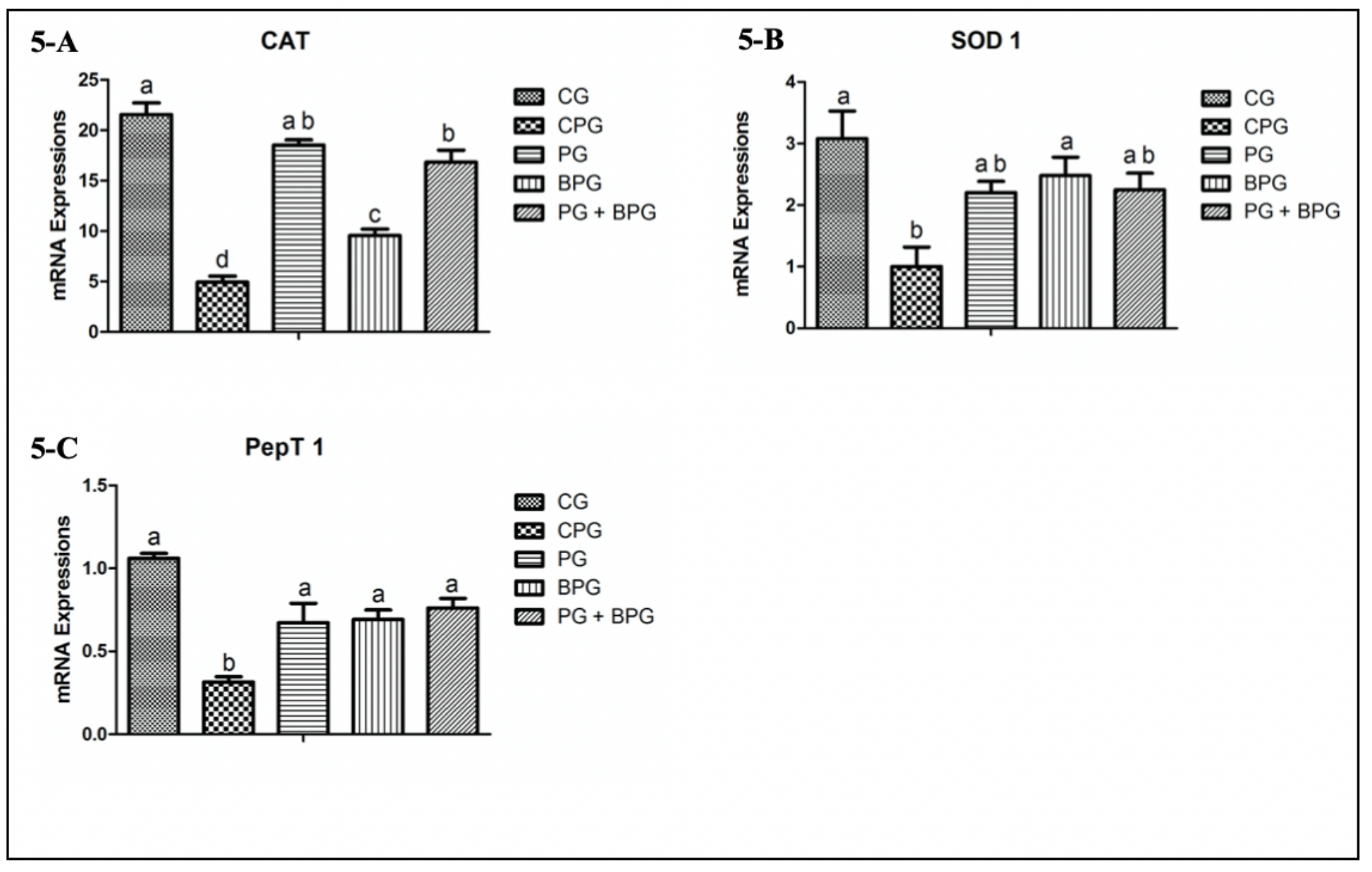

Figure 5

mRNA expressions associated with anti-oxidant enzymatic activity between un-treated and treated challenged are shown in Figure 5. Results are presented as mean and standard error of mean. Present superscripts $(a-d)$ show significant difference $((P<0.005)$ among the groups. $C G=$ Control group; $C P G=$ Control positive group; $P G=$ Probiotics group; $B P G=$ Bidens pilosa group; $P G+B P G=$ Probiotics + Bidens pilosa group. 


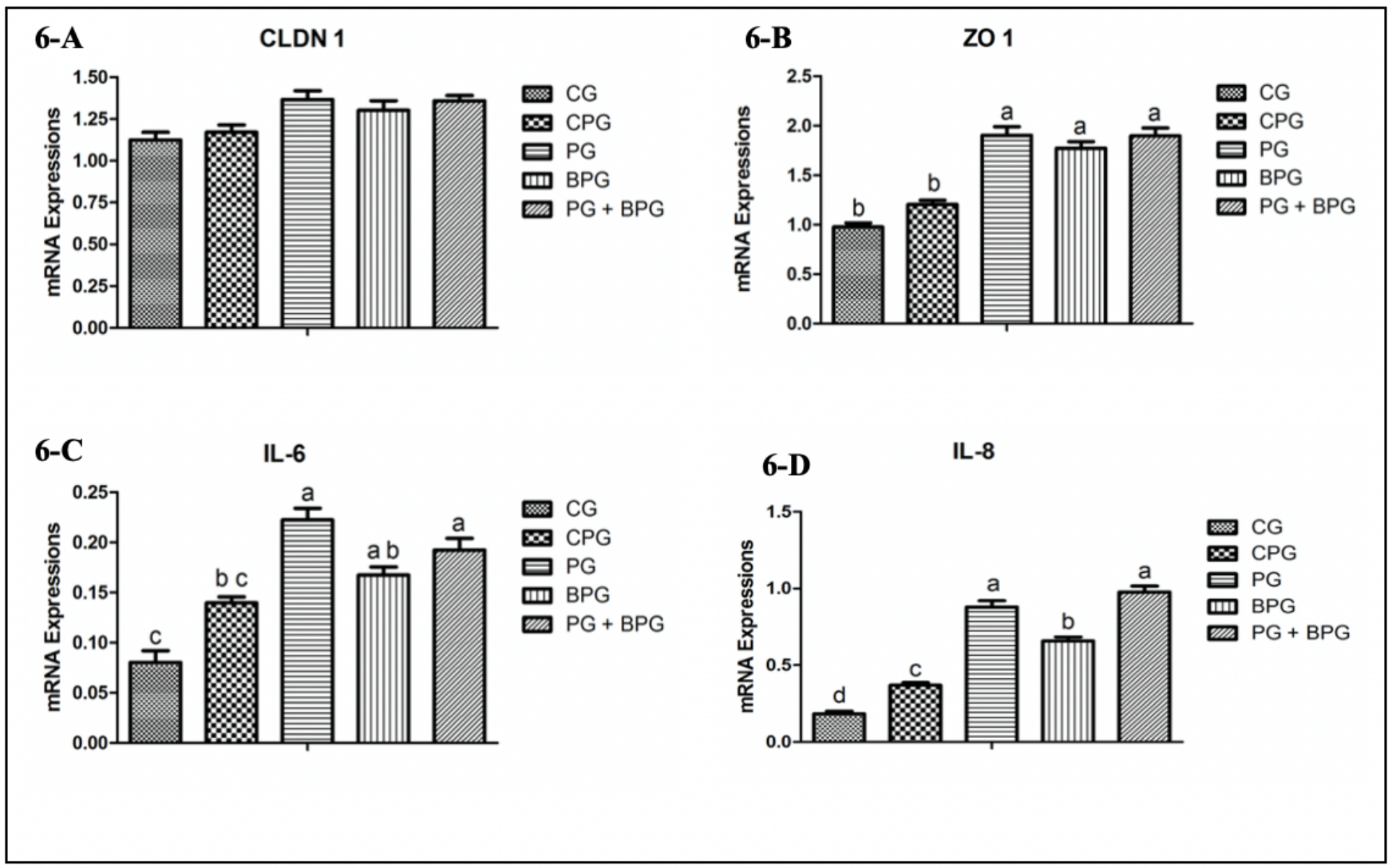

Figure 6

shows the mRNA expressions in the caeca related with pro-inflammatory cytokines and tight junction proteins of different groups. Results are presented as mean and standard error of mean. Present superscripts $(a-d)$ show significant difference $((P<0.005)$ among the groups. $C G=$ Control group; $C P G=$ Control positive group; $P G=$ Probiotics group; $B P G=$ Bidens pilosa group; $P G+B P G=$ Probiotics + Bidens pilosa group. 


\section{Mortality}

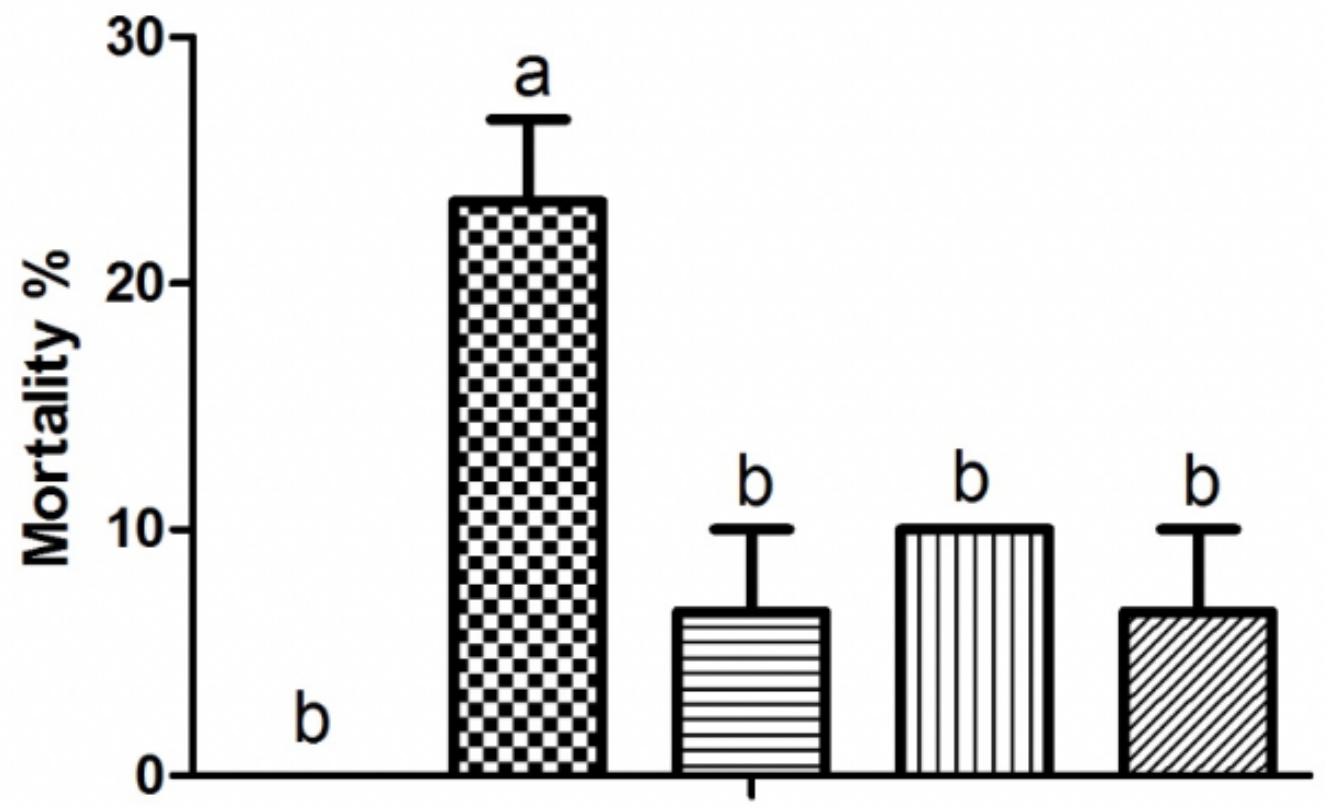

( $\mathrm{mG}$

EPG

曰PG

피 BPG

III $P G+B P G$

\section{Figure 7}

Total dead birds of all groups were counted and percentage of the mortality was calculated as is shown in Figure 7. Results are presented as mean and standard error of mean. Present superscripts (a-d) show significant difference $((P<0.005)$ among the groups. $C G=$ Control group; $C P G=$ Control positive group; $P G=$ Probiotics group; $B P G=$ Bidens pilosa group; $P G+B P G=$ Probiotics + Bidens pilosa group. 